\title{
Utilização de enxerto ósseo e fibrina rica em plaquetas (PRF) na Implantodontia: relato de caso
}

Use of bone graft and platelet-rich fibrine (PRF) in Implant Dentistry: clinical case

Uso de fibrina rica de injerto órgico y plaquetas (PRF) en la Odontología de Implantes: informe de caso

Janaina Soares da SILVA ${ }^{1}$

Rejane Kelly Andrade BEIRIZ ${ }^{1}$

Mariana Josue RAPOSO ${ }^{2}$

${ }^{1}$ Graduanda em Odontologia no Centro Universitário Tiradentes - UNIT, 57038-000 Maceió - AL, Brasil

${ }^{2}$ Professor do Centro Universitário Tiradentes - UNIT, 57038-000 Maceió - AL, Brasil

\section{Resumo}

O objetivo deste artigo é relatar um caso clínico no qual foi instalado dois implantes com a necessidade da utilização de enxerto ósseo, sendo associado com membrana de fibrina rica em plaquetas, visando à reabilitação do paciente. Paciente gênero feminino, 55 anos, compareceu ao consultório odontológico tendo como queixa principal à ausência das coroas dos elementos dentais 36 e 37. Desta forma, foi realizada a exodontia e em seguida foi instalado na região dois implantes, do tipo Titamax Cone Morse 4,1 X 11,5 da empresa *Neodent. A mesma tinha um defeito alveolar que resultou em um volume ósseo insuficiente, por conta disso foi inserido o enxerto ósseo com osso liofilizado bovino Bio-oss granulado (Geistlich*). O tratamento obteve um excelente resultado, tendo como consequência o sucesso cirúrgico com um pós-operatório sem complicações. De acordo com o caso relatado foi observado, que a fibrina rica em plaquetas associada ao enxerto Bio-Oss $\AA^{\circ}$ auxiliou e favoreceu no processo de reparo tecidual, contribuindo para aceleração e neoformação tecidual e óssea, fazendo assim uma reparação mais rápida do tecido, permitindo reabilitar o paciente em curto período de tempo e com biomaterial do próprio paciente.

Descritores: Enxerto Ósseo; Implantes Dentários; Plasma Rico em Plaquetas.

\section{Abstract}

The purpose of this article is to report a clinical case in which two implants were installed with the need for the use of bone graft, being associated with a fibrin membrane rich in platelets, aiming at the rehabilitation of the patient. Female patient, 55 years old, came to the dental office with the main complaint of the absence of crowns of dental elements 36 and 37 . Therefore, extraction was performed and then two implants, of the type Titamax Cone Morse 4, were installed in the region, $1 \mathrm{X} 11.5$ from the company * Neodent. It had an alveolar defect that resulted in an insufficient bone volume, for this reason the bone graft with granulated Bio-osseous bovine freeze-dried bone (Geistlich *) was inserted. The treatment obtained an excellent result, resulting in surgical success with a post-operative without complications. According to the reported case, it was observed that the platelet-rich fibrin associated with the Bio-Oss ${ }^{\circledR}$ graft helped and favored the tissue repair process, contributing to acceleration and tissue and bone neoformation, thus making a faster tissue repair, allowing rehabilitate the patient in a short period of time and with the patient's own biomaterial.

Descriptors: Grafting, Bone; Dental Implants; Platelet-Rich Plasma.

\section{Resumen}

El propósito de este artículo es reportar un caso clínico en el que se instalaron dos implantes con la necesidad del uso de injerto óseo, estando asociados a una membrana de fibrina rica en plaquetas, con el objetivo de la rehabilitación del paciente. Paciente de sexo femenino, de 55 años, acudió al consultorio odontológico teniendo como principal queja la ausencia de las coronas de los elementos dentales 36 y 37 . Por lo tanto, se realizó la extracción y luego se instalaron dos implantes, del tipo Titamax Cone Morse 4, en la región, 1 X 11,5 de la empresa * Neodent. Presentaba un defecto alveolar que resultaba en un volumen óseo insuficiente, por lo que se insertó el injerto óseo con hueso granulado bioóseo bovino liofilizado (Geistlich *). El tratamiento obtuvo un excelente resultado, resultando en éxito quirúrgico con un postoperatorio sin complicaciones. Según el caso reportado, se observó que la fibrina rica en plaquetas asociada al injerto Bio-Oss $®$ ayudó y favoreció el proceso de reparación tisular, contribuyendo a la aceleración y neoformación tisular y ósea, haciendo así una reparación tisular más rápida, permitiendo rehabilitar al paciente en un corto período de tiempo y con el biomaterial del propio paciente.

Descriptores: Injerto óseo; Implantes Dentales; Plasma Rico en Plaquetas.

INTRODUÇÃO

Após uma exodontia, é iniciado um processo de reparo no interior do alvéolo com a formação de um coágulo rico em células e fatores de crescimento. Durante essa etapa o rebordo alveolar passa por alterações importantes, resultantes da perda de osso alveolar devido à atrofia do rebordo edêntulo, causando um volume ósseo insuficiente, tanto em altura como em espessura. Uma vez que, essas alterações pode ser um fator limitante à possibilidade de reabilitação com implantes dentários, em função do volume ósseo insuficiente para sua execução, podendo ser indicado à utilização de enxertos para aumento da disponibilidade óssea ${ }^{1}$.

Atualmente, na implantodontia são utilizados enxertos ósseos como materiais biocompatíveis para reparação de defeitos ósseos, tendo como principal objetivo buscar a neoformação óssea. Os enxertos são classificados em três tipos: enxerto autógeno obtido e transplantado no mesmo indivíduo; o enxerto alógeno, obtido de um indivíduo e enxertado em outro indivíduo da mesma espécie; e o enxerto xenógeno, caracterizado pelo transplante ósseo entre indivíduos de diferentes espécies. Dentre os diferentes tipos de enxertos, o autógeno é considerado o "padrão ouro", pois possui propriedades antigênicas, angiogênicas e é o único que mantém propriedades osteogênicas, osteoindutoras e osteocondutoras ${ }^{2}$.

O enxerto xenógeno é uma boa alternativa em relação aos procedimentos reconstrutivos para a reabilitação de defeitos ósseos, permitindo deste modo o aumento do 
rebordo alveolar através dos enxertos em bloco. Para esse tipo de enxerto é bastante utilizado o osso bovino que é um dos materiais não autógenos. O Bio-Oss® (Geistlich Pharma AG, Wohlhusen, Suíça) é uma biocerâmica composta por hidroxiapatita de origem bovina desproteinizada e sua resistência biomecânica é similar ao do osso humano, proporcionando um volume adequado para a instalação do implante. Devido sua reabsorção extremamente lenta e alta osteocondutividade, os implantes com BioOss $\AA$ requerem significativamente maior força de remoção que os implantes controle, sendo umas das suas vantagens ${ }^{3}$.

Além disso, quando os enxertos ósseos são associados à Fibrina Rica em Plaquetas (PRF) observa-se aceleração da neoformação óssea e cicatrização dos tecidos moles. Assim, juntos possuem uma função protetora dos locais cirúrgicos e de biomateriais eventualmente implantados. A fibrina rica em plaquetas (PRF) faz parte da segunda geração de concentrados sanguíneos, foi idealizada por Joseph Choukroun em 2001 na França, como um biomaterial para utilização exclusivamente autóloga. Tem sido muito utilizado para regeneração óssea guiada associada a enxertos na implantodontia ${ }^{4}$.

A fibrina rica em plaquetas (PRF) segue um protocolo aberto, muito simples e pouco dispendioso. Sendo adquirida através da centrifugação do sangue do paciente em tubos de plástico ou de vidro secos, sem adição de qualquer anticoagulante, imediatamente submetido a uma única centrifugação suave. Após este processo três camadas são formadas: na primeira camada onde é observado um líquido transparente vai ter o plasma, segunda camada espessa e amarela é encontrada um concentrado de fibroblastos e fatores de crescimento na qual se forma o coágulo de fibrina, e a terceira camada de cor vermelha são os glóbulos vermelhos ${ }^{5}$.

Pode-se obter a fibrina rica em plaquetas (PRF) tanto na forma líquida quanto na forma de membrana, e elas são classificadas em fibrina pura rica em plaquetas (P-PRF), e fibrina rica em plaquetas e leucócitos (L-PRF). A principal diferença entre elas são os métodos pelos quais são obtidas, a centrifugação e o tempo, visto que o processo de centrifugação da membrana vai ser em uma maior velocidade em um tempo de 10 minutos, já do líquido vai ser em uma menor velocidade em um menor tempo entorno de 5 minutos 6 .

Apresentam-se como uma matriz autóloga de fibrina, plaquetas, leucócitos, citocinas, fatores de crescimento e demais componentes do plasma sanguíneo que iram ser liberadas até 28 dias após o procedimento, proporcionando a conversão de fibrinogênio em uma rede de fibrina, com liberação de fatores de crescimento, com o propósito de promover a angiogênese, ativação e quimiotaxia de fibroblastos e consequentemente aceleração da reparação tecidual ${ }^{7}$.

Além disso, possui a habilidade de regular a inflamação e de estimular o processo imunológico da quimiotaxia e, este sendo um material autólogo, tem a capacidade de eliminar qualquer risco de transmissão de doenças. De todas as aplicações clínicas conhecidas deste composto, é de suma importância destacar a aceleração da cicatrização tecidual devido ao desenvolvimento de neovascularização, com ausência quase total de eventos infecciosos. Este biomaterial foi elaborado para aumentar o crescimento e a proliferação dos osteoblastos, após o mesmo proporciona uma redução do tempo de cicatrização dos tecidos moles e consequentemente uma redução na dor pós-operatória ${ }^{8}$.

O objetivo deste artigo é relatar um caso clínico no qual foi instalado dois implantes com a necessidade da utilização de enxerto ósseo, sendo associado com membrana de fibrina rica em plaquetas, visando à reabilitação do paciente.

CASO CLÍNICO

Paciente gênero feminino, 55 anos, compareceu ao consultório odontológico para a realização de um implante dentário, tendo como queixa principal à ausência das coroas dos elementos dentais 36 e 37 , e a paciente também relatava que queria uma melhora na função mastigatória e estética. Após anamnese e exame clínico, foi solicitada uma radiografia e tomografia para avaliação dos elementos dentais 36 e 37 (Figura 1), sendo posteriormente indicado a exodontia dos mesmos, pois não tinha como recuperar as raízes desses dentes visto que elas estavam fragilizadas (Figura 2). Em seguida, foi realizada a instalação dos dois implantes, do tipo Titamax Cone Morse 4,1 X 11,5 da empresa *Neodent (Figura 3). A mesma tinha um defeito alveolar que resultou em um volume ósseo insuficiente, por conta disso foi inserido o enxerto ósseo com osso liofilizado bovino Bio-oss granulado $\left(\right.$ Geistlich $^{*}$ ) (Figura 4). Além disso, para confecção da membrana de fibrina rica em plaquetas (PRF) foi realizado no paciente uma coleta de sangue (Figura 5), após coleta dos tubos, estes foram posicionados na centrífuga horizontal, sendo utilizado um tubo preenchido com água com finalidade de manter o equilíbrio 
para centrifugação durante cinco minutos, com velocidade de 3300rpm. Com o término deste processo, é possível observar uma área de cor alaranjada no tubo, sendo neste caso a membrana de fibrina rica em plaquetas (PRF) e o restante do material sanguíneo logo abaixo.

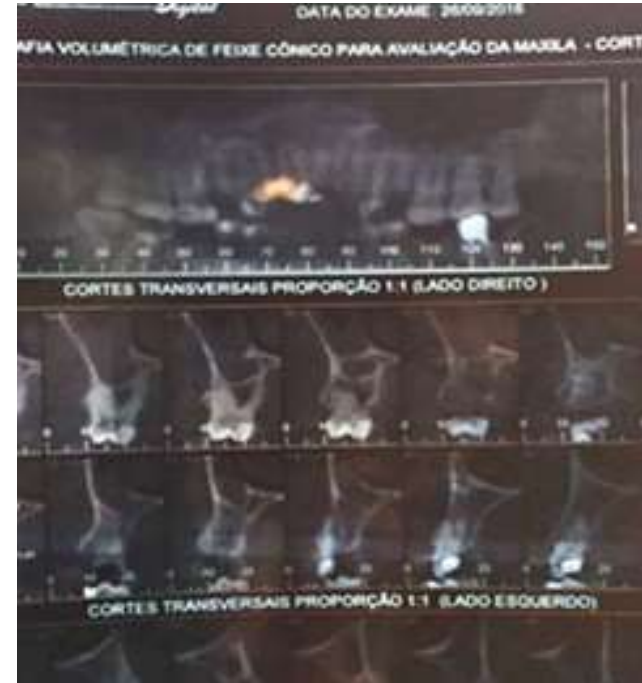

Figura 1: Tomografia para avaliação dos dentes.

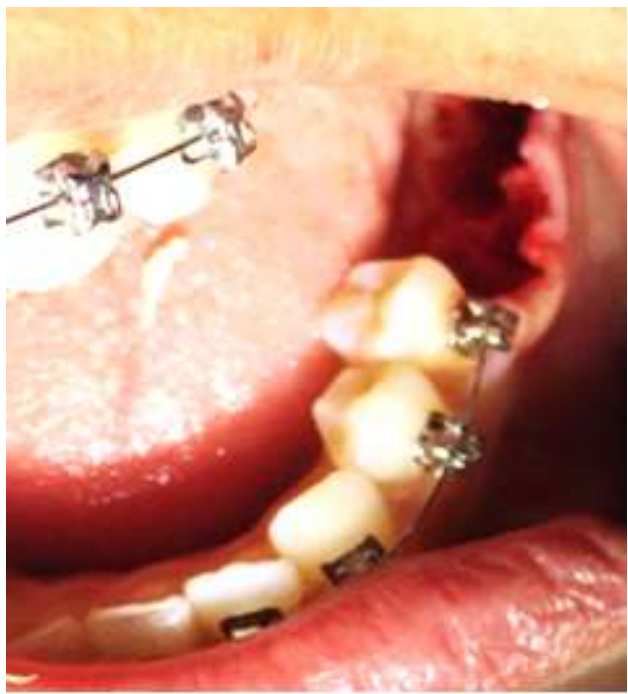

Figura 2: Após a exodontia dos dentes 36 e 37

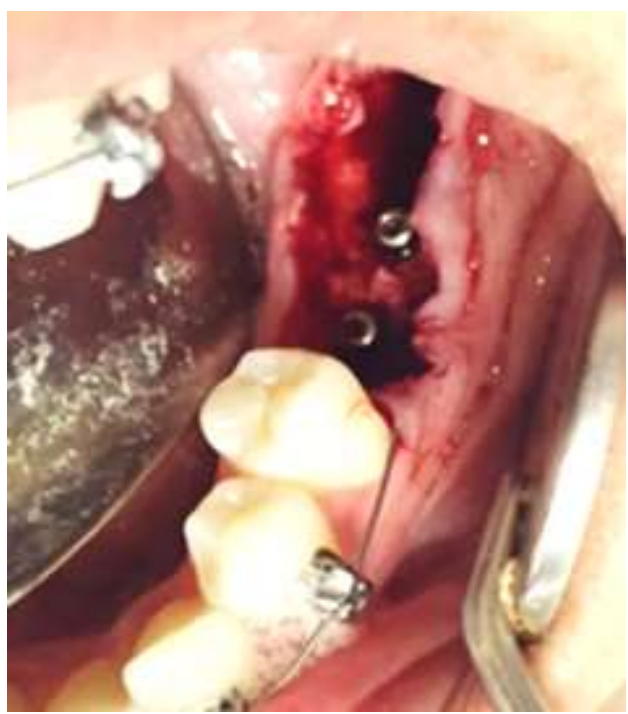

Figura 3: Instalação imediata de implantes cone morse Neodent.

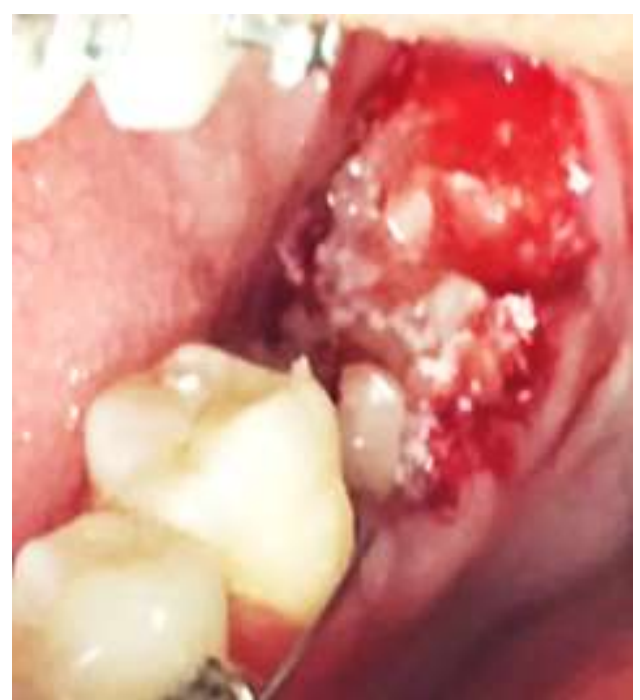

Figura 4: Enxerto ósseo com osso liofilizado bovino Bio-oss granulado Geistlich* no defeito ósseo.

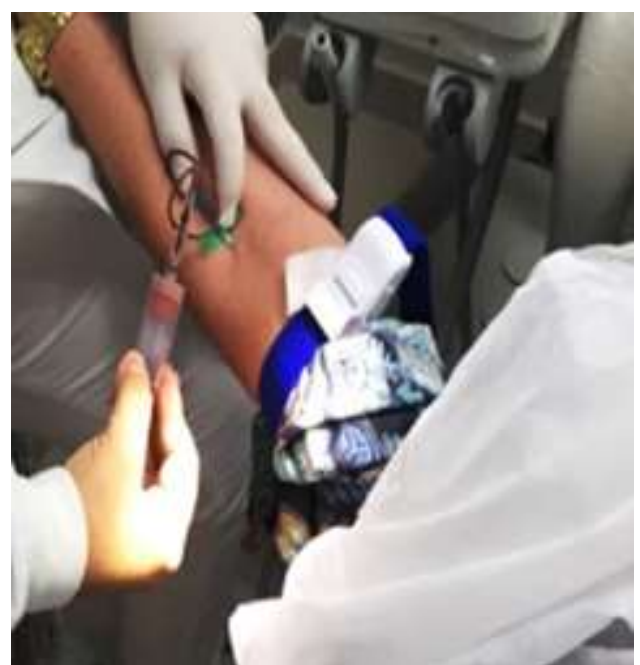

Figura 5: Coleta de sangue no paciente, para síntese da membrana de fibrina rica em plaquetas (PRF).

Em seguida, os tubos foram abertos de forma cuidadosa, para não acontecer à homogeneização do material, foi utilizado uma pinça para retirada da membrana de fibrina rica em plaquetas (PRF) (Figura 6), e as mesmas foram colocadas cuidadosamente em uma caixa metálica (Figura 7).

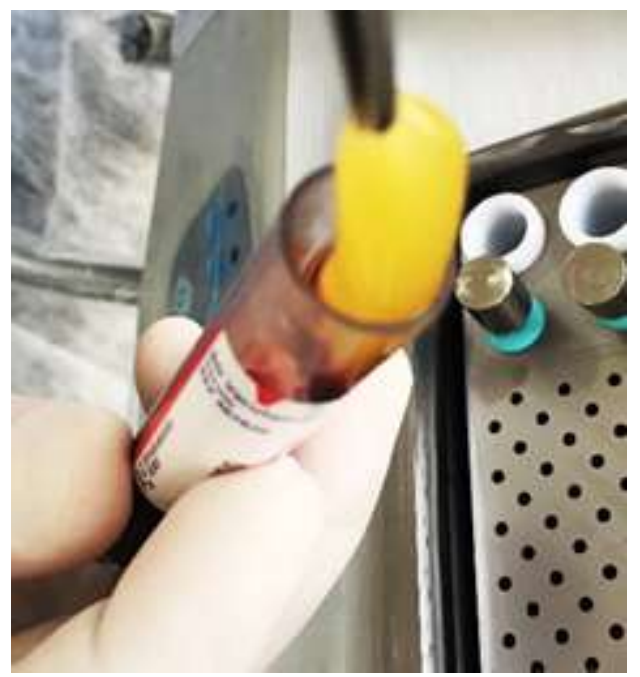

Figura 6: Concentrado de PRF sendo retirado do sangue. 


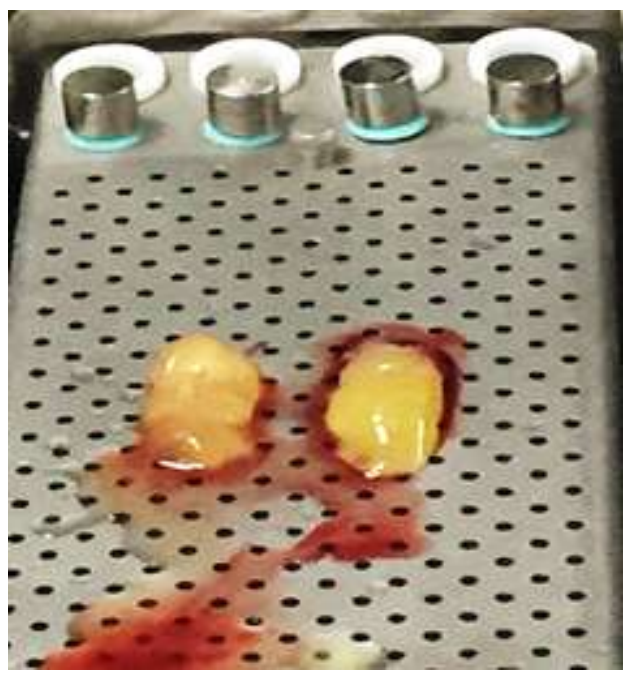

Figura 7: Colocação do concentrado de PRF em caixa metálica.

Posteriormente as membranas foram prensadas para extração de todo líquido formando uma fina película da membrana de fibrina rica em plaquetas (PRF) (Figura 8), em seguida as membranas foram instaladas na região para o fechamento do espaço alveolar (Figura 9). Sendo realizada sutura com fio de seda 3-0 pontos simples (Figura 10).

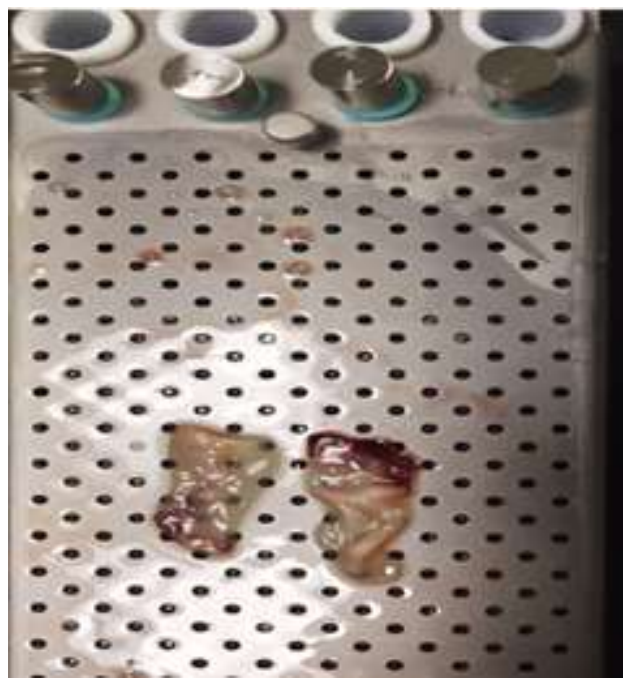

Figura 8: Formação de uma fina película da membrana de fibrina rica em plaquetas (PRF).

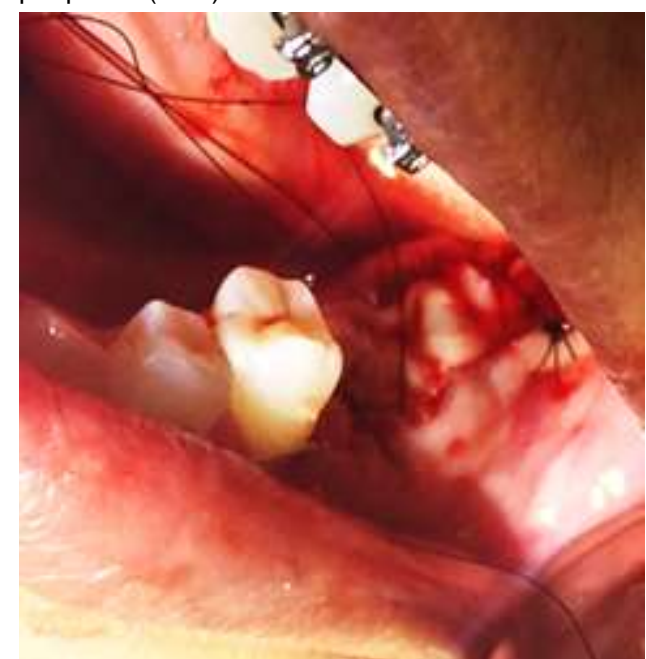

Figura 9: Instalação da membrana de PRF para fechamento do espaço alveolar.

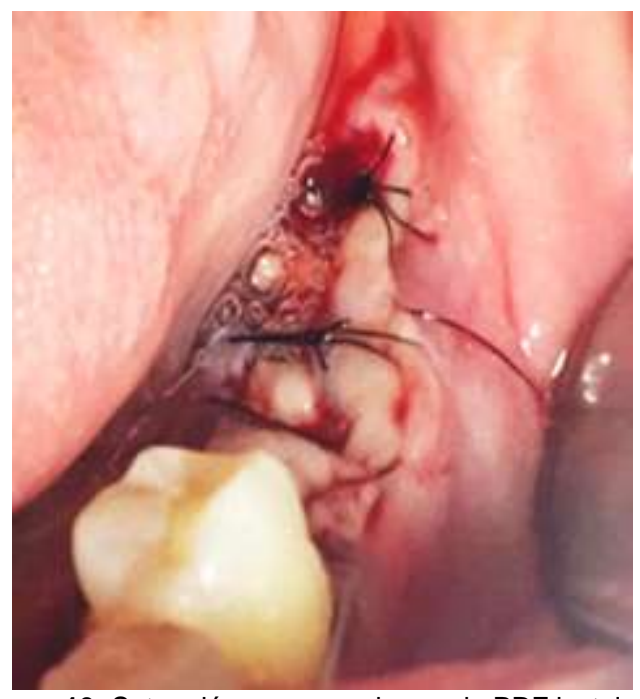

Figura 10: Sutura já com a membrana de PRF instalada.

Prescrição medicamentosa foi antibiótico (amoxicilina $500 \mathrm{mg}, 8 / 8 \mathrm{hs}$, durante 07 dias) AINES (ibuprofeno 600mg, 8/8hs, durante 05 dias) e analgésico (dipirona 500mg, 6/6hs, durante 03 dias) e orientações quanto à higiene bucal, alimentação líquida pastosa, fria e gelada por 02 dias, repouso relativo e retorno com 07 dias. É possível observar após 07 dias do procedimento cirúrgico a completa regeneração e envolvimento da membrana de PRF aos tecidos gengivais, apresentando excelente cicatrização. O tratamento obteve um excelente resultado, tendo como consequência o sucesso cirúrgico com um pós-operatório sem complicações.

DISCUSSÃO

A reabilitação com implantes em indivíduos edêntulos parcial ou total oferece uma melhor qualidade de vida aos pacientes. Esse procedimento pode ser realizado de uma forma imediata, ou seja, no momento da extração dentária, ou tardia, após um pequeno período de cicatrização óssea e gengival, além disso, a instalação de implantes logo após a exodontia se torna cada vez mais um protocolo cirúrgico habitual nas reabilitações orais, por conta da paralisação da reabsorção óssea, e consequentemente da preservação da arquitetura gengival, proporcionando assim um melhor resultado estético. No presente caso, foi realizada a instalação dos implantes de forma imediata, concordando assim com a literatura ${ }^{9}$.

A osseointegração de implantes dentários é definida como uma união estrutural e funcional entre o osso recém formado e a superfície do implante, que acabou se tornando um sinônimo do conceito biomecânico de estabilidade secundária. $O$ autor ainda relata que a osseointegração compreende uma cascata de mecanismos complexos e 
fisiológicos semelhantes à cicatrização direta das fraturas. Sendo importante destacar que o processo osteogênico requer uma cuidadosa coordenação cronológica e espacial dos sinais moleculares, levando à proliferação, migração e diferenciação das células precursoras mesenquimais em osteoblastos. Por outro lado, os implantes osseointegrados surgiram como um novo meio de escolha para o tratamento, e como opção de reabilitação oral ${ }^{10}$.

Durante a instalação do implante, a formação óssea ao redor do implante de titânio é ativada quando a matriz é exposta ao fluido extracelular, liberando proteínas não colágenas e fatores de crescimento. Um dos principais fatores que influenciam diretamente o processo de osseointegração é a formação de selamento da mucosa, que é a única barreira física capaz de não permitir a interferência do ambiente externo na formação óssea ${ }^{11}$.

Para o sucesso da instalação dos implantes, é de suma importância que se tenha um leito ósseo hospedeiro saudável e compatível, permitindo deste modo, a estabilidade primária e, por seguinte a osseointegração $^{12}$. No entanto, essa fase não é vista com frequência, por conta que muitos pacientes apresentam um tecido ósseo que já sofreu anteriormente irradiação, apresentando diferentes graus de reabsorção óssea que resultam em um volume ósseo insuficiente para a instalação dos implantes. O caso relatado está de acordo com a literatura, visto que a paciente tinha um defeito alveolar que resultou em um volume ósseo insuficiente, para instalação dos implantes ${ }^{13}$.

Em vista disto, as condições ósseas ideais para a instalação dos implantes em altura e largura óssea é de $4 \mathrm{~mm}$ x $10 \mathrm{~mm}$. A colocação de implantes em áreas com quantidade óssea insuficiente é inviável, e ao ser realizado, pode provocar grandes defeitos estéticos e funcionais após a reabilitação protética. Visto que, o volume ósseo defeituoso, tanto em altura como em espessura, é o principal problema clínico mais comum na reabilitação com implantes dentários e que condiz a uma indicação de enxertos ósseos para aumento da estrutura do tecido óssea ${ }^{14}$.

A osseointegração trouxe inúmeros benefícios, como uma melhor retenção e uma adequada estabilidade às reabilitações, com excelentes resultados ao longo do tempo. Sendo importante ressaltar, mesmo que seu índice de sucesso seja alto, acima de 90\%, algumas falhas poderão ocorrer ${ }^{15}$. Ademais a principal falha do implante devido à osseointegração insuficiente ocorre em 1-2\% dos pacientes nos primeiros meses. A falha secundária do implante se desenvolve vários anos após a osseointegração bem sucedida em cerca de $5 \%$ dos pacientes e é geralmente causada por peri-implantite. Visto que esses dados da literatura não conferem com o caso clínico, não havendo nenhuma falha na instalação dos implantes referente à sua osseointegração ${ }^{10}$.

Desta forma, são utilizados diversos tipos de biomateriais para suprir a necessidade de suportar a carga oclusal e também como opções terapêuticas para preservação e recuperação dos rebordos edêntulos, tais quais, fibrina rica em plaquetas (PRF) e enxertos ósseos que podem ser autógeno, alógeno ou xenógeno ${ }^{16}$.

Alguns autores concordam que os enxertos autógenos já são considerados na literatura como um material padrão ouro para reconstrução de processos alveolares atróficos devido às suas inúmeras propriedades e as pequenas chances de rejeição ${ }^{2}$. No entanto, esse tipo de enxerto possui algumas desvantagens como a necessidade de área doadora intra ou extrabucal e o tempo transoperatório, e por esses motivos existem um grande desenvolvimento de pesquisas em biomateriais na implantodontia que apresentam propriedades semelhantes a este tipo de enxerto, como por exemplo, os biomateriais xenógenos ${ }^{17}$.

Esse tipo de biomaterial está cada vez mais em evidência devido às suas propriedades semelhantes às do osso autógeno, tendo como a vantagem de não haver a necessidade de um segundo sítio cirúrgico, eliminando a questão da morbidade e da quantidade limitada de material disponíve ${ }^{18}$. Por outro lado, o enxerto xenógeno também pode apresentar uma elevada biocompatibilidade e um curto tempo de remodelação óssea, mantendo assim o volume ósseo por um tempo mais longo. Sendo tal informação compatível com o caso relatado, visto que foi escolhido o enxerto xenógeno para correção de defeito ósseo, confirmando desta forma as inúmeras vantagens e benefícios que este tipo de biomaterial pode proporcionar ${ }^{19}$.

Além disso, um exemplo de enxerto xenógeno muito utilizado na implantodontia é o Bio-Oss $\AA$. Apesar de, este tipo de biomaterial ser de origem bovina desproteinizado, estudos declaram que na sua preparação, pode haver uma menor quantidade de proteínas, as quais estariam interligadas com a fase mineral. Inclusive, mesmo que existam remanescentes orgânicos no Bio-Oss $\AA$, este biomaterial xenógeno é biocompatível, uma vez que ele não 
é reconhecido como um corpo estranho. Os autores ainda consideram este material osteocondutor, pode reabsorver aos poucos, e consequentemente ser substituído por osso lamelar permanecendo assim em íntimo contato com o implante ${ }^{16}$.

Acrescenta-se que o Bio-Oss $\AA$ na sua forma granulosa tem ganhado um excelente destaque na odontologia, sendo considerado um material confiável e indicado para tais procedimentos, uma vez que são capazes de promover a osteogênese normal. Além do mais, as partículas de Bio-Oss ${ }^{\circledR}$ auxiliam na manutenção do volume ósseo, pois acaba se tornando um componente da estrutura óssea neoformada. Por conta do seu alto teor de porosidade, o biomaterial deve ocupar apenas entre $25 \%$ e $30 \%$ do defeito a ser corrigido, permitindo que tenha espaço suficiente para que ocorra uma nova formação de tecido. Outro ponto positivo nesse biomaterial que seja importante ressaltar é a sua extensa área de superfície interna, o que acaba facilitando na absorção de proteínas endógenas. Portanto, foi utilizado no presente caso o enxerto xenógeno do tipo Bio-Oss ${ }^{\circledR}$ granulado, concordando assim com os benefícios demonstrados na literatura ${ }^{17}$.

Durante o decorrer dos anos várias técnicas foram desenvolvidas para impulsionar a reconstrução de tecidos moles e óssea. E por conta disso, foram aperfeiçoados vários tipos de biomateriais naturais, sendo que esses biomateriais devem passar por diferentes estágios de processamento para eliminação de patógenos e assim minimizar o risco de doenças $^{20}$. Por outro lado, os biomateriais sintéticos são fabricados de maneira imitativa e não exibem semelhança com a estrutura do tecido nativo e a bioatividade de biomateriais naturais. Por isso, os concentrados sanguíneos foram introduzidos como um método clinicamente importante, como uma forma de identificar fontes de regeneração autóloga minimamente invasiva. Os concentrados de sangue são gerados a partir do sangue periférico do próprio paciente, concentrado por centrifugação e podem liberar diferentes fatores de crescimento, dentre eles a fibrina rica em plaquetas (PRF) ${ }^{21}$.

Embora inúmeras células desempenhem um importante papel na biologia deste biomaterial, mas é a matriz de fibrina que estabelece 0 elemento determinante responsável pelos principais benefícios terapêutico da fibrina rica em plaquetas (PRF). Sendo, uma matriz constituída por todos os elementos moleculares e celulares, permitindo a cura ideal carregando assim, todos os elementos favoráveis inclusos em uma amostra de sangue. No presente caso foi abordado associação dos dois biomateriais, devido às suas propriedades que ajuda na regeneração óssea e na cicatrização e seus efeitos satisfatórios causados no tecido ósse ${ }^{22}$.

Além disso, fibrina rica em plaquetas (PRF) age como um adesivo biológico mantendo as partículas em ordem, facilitando assim a manipulação dos enxertos ósseos. Inclusive, a membrana de fibrina atua como uma barreira biológica, fornecendo proteção aos implantes e enxertos, agindo como uma bandagem de fibrina ${ }^{23}$. Em vista disso, a membrana de fibrina acelera o processo de osseointegração, bem como o provável aumento da estabilidade primária nas duas primeiras semanas após a instalação dos implantes ${ }^{7}$. Ela é também considerada por alguns autores um excelente biomaterial propício para aumento de rebordos no exato momento da instalação dos implantes imediatos, desde que se tenha uma adequada estabilidade. Sendo tal informação compatível com abordagem descrita no caso relatado ${ }^{2,11}$.

Deste modo, o uso da fibrina rica em plaquetas (PRF) é capaz de reduzir a dor e o edema no pós-operatório e também limitar a infecção. Contudo, para esta técnica obter-se sucesso satisfatório é necessário, realizar este procedimento em uma boa agilidade tanto na coleta do sangue como na sua transferência para centrifugadora, visto que a mostra quando entra em contato com o vidro do tubo já inicia o seu o processo de coagulação. Se por caso, o cirurgião-dentista não tenha o domínio da técnica, a fibrina irá se polimerizar se espalhando em várias direções do tubo e só será obtido um pequeno coágulo sem consistência. Através do trabalho disposto, o tratamento obteve um resultado satisfatório devido à agilidade do operador e o paciente evoluiu com ausência de complicações póscirúrgicas, confirmando desta forma os dados literários ${ }^{24}$.

CONCLUSÃO

De acordo com o caso relatado foi observado, que a fibrina rica em plaquetas associada ao enxerto Bio-Oss $\AA$ auxiliou e favoreceu no processo de reparo tecidual, contribuindo para aceleração e neoformação tecidual e óssea, fazendo assim uma reparação mais rápida do tecido, permitindo reabilitar o paciente em curto período de tempo e com biomaterial do próprio paciente. O tratamento obteve um resultado satisfatório para 0 paciente, decorrente da ausência de complicações pós-cirúrgicas. 


\section{REFERÊNCIAS}

1. Klassmann FA, Coró ER, Thomé G, Melo ACM, Sartori IAMS. Enxertos ósseos autógenos de áreas doadoras intra-bucais e procedimentos clínicos integrados possibilitando reabilitação estética e funcional. RGO. 2002;54(4):388-92.

2. Alves RTC, Raoni, Silva LAD, Figueiredo ML, Ribeiro ED, Silva JSP, Germano AR. Enxertos ósseos autógenos intrabucais em implantodontia: estudo retrospectivo. Rev cir traumatol buco-maxilo-fac. 2014;14(4):9-16.

3. Loyola M, Ancoski T, Ramires MA, Mello F, Mello AMD. Enxertos ósseos autógenos e xenógenos como alternativa de manutenção do espaço alveolar. RGS. 2018;19(2):8-18.

4. Choukroun J, Adda F, Schoeffler C, Vervelle A. Une opportunite' en paro-implantologie: le PRF. Implantodontie. 2001;42(5):55-62.

5. Takamori ER, Telles MV, Texeira MVT, Menezes K, Carias RBV, Boeojevic R. Fibrina rica em plaquetas: preparo, definição da qualidade, uso clínico. Vigil. sanit. debate. 2018;6(1):118-24.

6. Ehrenfest DMD, Rasmusson L, Albrektsson T. Classification of platelet concentrates: from pure platelet-rich plasma (P-PRP) to leucocyteand platelet-rich fibrin (L-PRF). Trends In Biotechnology. 2009;27(3):35-59.

7. Masetto VL. Reabilitação com Implantes Associado ao uso de PRF e Acompanhamento Radiográfico: Relato de caso clínico [dissertação]. Curitiba: Faculdade de Curitiba, ILAPEO; 2018.

8. Azevedo MCPS, Gomes PS. Aplicação do PRF em medicina dentária [dissertação]. Porto: Faculdade de Medicina Dentária da Universidade do Porto; 2014.

9. Vignoletti $F$, Johansson C, Albrektsson T, De sanctis M, San roman F, Sanz M. Early healing of implants placed into fresh extraction sockets: an experimental study in the beagle dog. De novo bone formation. J Clin Periodontol. 2009;36(5):265-77.

10. Smeets R, Stadlinger B, Schwarz F, BeckBroichsitter B, Jung O, Precht C, Kloss F, Gröbe A, Heiland M, Ebker T. Impact of Dental Implant Surface Modifications on Osseointegration. Biomed Res Int. 2016;2016:6285620.

11. Costa LC, Fonseca MAD, Pinheiro ADR, Aguiar TRDS, Machado AN, Quinelato V, Bonato LL, Aguiar DP, Vieira T, Almeida FLD, Lobo JC, Jordão M, Lomardo PG, Granjeiro JM, Casado PL. Chronic Periodontitis and RANKL/OPG Ratio in Peri-Implant Mucosae Inflammation. Braz Dent J. 2018;29(1):14-22.

12. Silva FL, Rodrigues F, Pamato, Pereira S, Pereira JR. Tratamento de superfície em implantes dentários: uma revisão de literatura. RFO UPF. 2016;21(1):136-42.
13.Zavanelli RA, Guilherme AS, Castro AT, Fernandes JMA, Pereira REP, Garcia RR. Fatores locais e sistêmicos relacionados aos pacientes que podem afetar a osseointegração. Rev Gaúch Odontol. 2011; 59(1):133-46.

14. Salmen FS, Oliveira MR, Gabrielli MAC, Piveta ACG, Filho VAP, Gabrielli MFR. Enxerto ósseo para reconstrução óssea alveolar. Revisão de 166 casos. Rev Col Bras Cir. 2017;44(1):33-40.

15. Dentz DCV, Barcellos MS, Anziliero AH, Correa J, Marchiori PM, Takemoto MM. Osseointegração em implantes. 2018;8(2): 358-81.

16. Pilger AA, Schneider LE, Silva GM, Schneider KCC, Smidt R. Biomateriais de substituição óssea para procedimentos de reconstrução alveolar em implantodontia. Rev Ciênc Méd Biol. 2018;17(1):102-7.

17. Fardin AC, Jardim ECG, Pereira FC, Guskuma $\mathrm{MH}$, Aranega M, Garcia IRJ. Enxerto ósseo em odontologia: revisão de literatura. Innov. Implantar. J Biomater Esthet.2010;5(3):48-52.

18. Rodolfo LM, Machado LG, Faeda RS, Queiroz TP, Faloni APS. Substitutos ósseos alógenos e xenógenos comparados ao enxerto autógeno: reações biológicas. ReBraM. 2017;20(1): 89-102.

19. Issa SK, Paterno D. Uso do biomaterial biooss $\AA$ em enxertos ósseos na implantodontia [monografia] São Paulo: Faculdade de Sete Lagoas; 2019.

20. Al-Maawi S, Herrera-Vizcaino C, Dohle E, Zrnc TA, Parvini $P$, Schwarz $F$ et al. Homogeneous pressure influences the growth factor release profiles in solid platelet-rich fibrin matrices and enhances vascular endothelial growth factor release in the solid platelet-rich fibrin plugs. Int J Growth Factors Stem Cells Dent. 2018;1(1): 8-16.

21. Strauss FJ, Stähli A, Gruber R. The use of platelet-rich fibrin to enhance the outcomes of implant therapy: A systematic review. Clin Oral Implants Res. 2018;29(Suppl 18):6-19.

22. Choukroun J, Diss A, Simonpieri A, Girard MO, Schoeffler C, Dohan SL, Dohan AJ, Mouhyi J, Dohan DM. Platelet-rich fibrin (PRF): a secondgeneration platelet concentrate. Part IV: clinical effects on tissue healing. Oral Surg Oral Med Oral Pathol Oral Radiol Endod. 2006;101(3):e56-60.

23. Dohan DM, Choukroun J, Diss A, Dohan SL, Dohan AJ, Mouhyi J, Gogly B. Platelet-rich fibrin (PRF): a second-generation platelet concentrate. Part I: technological concepts and evolution. Oral Surg Oral Med Oral Pathol Oral Radiol Endod. 2006;101(3):e37-44.

24. Toffler M, Toscano N, Holtzclaw D, Del Corso M, Dohan Ehrenfest DM. Introducing Choukroun's platelet rich fibrin (PRF) to the reconstructive Surgery Milieu. J Implant Advanced Clin Dent. 2009;1:21-31. 


\section{CONFLITO DE INTERESSES}

Os autores declaram não haver conflitos de interesse

\section{AUTOR PARA CORRESPONDÊNCIA}

\section{Janaina Soares da Silva}

Centro Universitario Tiradentes - UNIT

Departamento de Odontologia

Av. Comendador Gustavo Paiva, 5017, Cruz das almas,

Cep: 57038-000, Maceió-AL, Brasil, +55 (82) 3311-3100

E-mail: janainasooaressilva@hotmail.com 